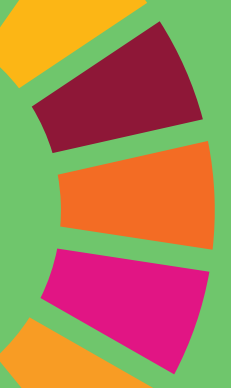

\title{
ÉTICA Y DERECHO EN LA REVOLUCIÓN DIGITAL
}

\section{ETHICS AND LAW IN THE DIGITAL REVOLUTION}

"La ética es como el oxígeno; nos acordamos de ella cuando falta." (Amartya Sen)

\author{
Txetxu Ausín, \\ Instituto de Filosofía del CSIC \\ txetxu.ausin@cchs.csic.es \\ Margarita Robles Carrillo \\ Universidad de Granada \\ mrobles@ugr.es
}

Fecha recepción artículo: 06/11/2020 • Fecha aprobación artículo: 09/12/2020

\section{RESUMEN}

La digitalización y sus tecnologías asociadas, como la IA y la ciencia de datos masivos, incorporan una moralidad -aunque solo sea por su enorme poder transformador - de la que tenemos que hacernos cargo (responsabilizarnos) por las vías de la ética y del derecho. Ética y Derecho son dos instrumentos diferentes pero altamente interdependientes para abordar los bienes y deberes en torno a la digitalización y sus muchas oportunidades - por ejemplo para la consecución de los Objetivos de Desarrollo Sostenible- y, a la vez, los enormes desafíos que se plantean para la propia identidad y relaciones humanas, los derechos y la política.

Palabras clave: Revolución, Digital, Moral, Responsabilidad, Ética, Derecho.

\section{ABSTRACT}

Digital Revolution and its associated technologies, such as Al and mass data science, embody a morality - if only because of their enormous transformative power - that must be taken care of (made responsible) by the ways of ethics and law. Ethics and Law are two different but highly interdependent instruments to address the goods and obligations around digitalization and its many opportunities - for example for the achievement of the Sustainable Development Goals - and at the same time the enormous challenges to human identity and relations, rights and politics.

Keywords: Revolution, Digital, Moral, Responsibility, Ethics, Law. 


\section{UN NUEVO MUNDO}

La digitalización y los procesos tecnológicos asociados a ella se conciben como una enorme revolución económica y social, la llamada Cuarta Revolución industrial. ${ }^{1}$ Esto es especialmente relevante, por ejemplo, en ámbitos de interés social como la salud pública, donde la IA y la ciencia de datos permiten predecir la expansión de epidemias, descubrir efectos secundarios en los medicamentos, establecer medidas contra la contaminación ambiental, etc. A través de la digitalización podemos ahora capturar y calcular a una escala mucho más amplia los aspectos físicos e intangibles de la existencia y actuar sobre ellos. Además, la automatización ligada a la digitalización podrá liberar al ser humano de tareas peligrosas o alienantes. La economía de la transformación digital puede cambiar nuestros modos de ver y hacer las cosas y generar nuevos modelos de emprendimiento, como la innovación a través de la cooperación (inteligencia colectiva y experimentación abierta). Las políticas públicas basadas en datos contribuirán a modelos decisionales menos especulativos, a reducir riesgos e incertidumbres, aunque no cabe reducir toda la inteligencia social a la toma de decisiones (decisionismo). Igualmente, las políticas de datos abiertos contribuyen a la transparencia y la rendición de cuentas de las administraciones públicas, favoreciendo la participación y el compromiso ciudadano con las políticas públicas (public engagement).

Importantes áreas de África, Asia o América se encuentran en profunda transformación de la mano de la telefonía móvil. Las posibilidades de acceder a la sanidad digital, la educación online o los mercados transforman sus sociedades.

El llamado "Internet de (todas) las Cosas" (IoT) va a suponer una explosión de artefactos e instrumentos, altamente interconectados, que no solo recogen enormes cantidades de información, sino que la procesan, cruzan y reutilizan para tomar decisiones en ámbitos variados de la vida social: desde la medicina, hasta la alimentación; desde las finanzas, hasta el transporte; desde la educación hasta los deportes. Más aún, entramos en la fase del "Internet de los Cuerpos" (loB), con un número sin precedentes de dispositivos y sensores conectados que se fijan o incluso se implantan e ingieren en el cuerpo humano. Esto ha convertido al cuerpo humano en una plataforma tecnológica. La loB genera enormes cantidades de datos biométricos y de comportamiento humano. Esto, a su vez, está impulsando la transformación de la investigación sanitaria y la industria, así como otros aspectos de la vida social, como la adopción de la loB en el ámbito laboral o la provisión de nuevas opciones de entretenimiento, todo ello con notables innovaciones basadas en datos y beneficios sociales.

Cada vez más nos configuramos como sistemas sociotécnicos donde todas nuestras interrelaciones están mediadas tecnológicamente; mantenemos una interacción física, cognitiva y hasta emocional con la tecnología (Human-Machine Interaction HMI; equipos de seres humanos trabajan con máquinas en una suerte de simbiosis entre la inteligencia humana y la artificial: Human-in-the-loop). Las tecnologías convergentes y disruptivas también están difuminando las fronteras entre los sujetos humanos y la tecnología (Multi-Agent Systems). En este sentido, valores tradicionalmente reservados a los seres humanos (como autonomía, responsabilidad, creatividad) están empezando a proyectarse en las entidades tecnológicas, a menudo impulsadas por nuestra tendencia al antropomorfismo.

\footnotetext{
${ }^{1}$ Una revolución 4.0 que se concreta en la convergencia de tecnologías digitales, físicas y biológicas que evolucionan a gran velocidad. Son las Ilamadas NBIC: nanotecnologías, biotecnologías, tecnologías de la información y ciencias cognitivas (IA, ciencia de datos, robótica, $\mathrm{BCl}$, biología sintética, nanotecnología).
} 
Se está produciendo una digitalización de (toda) la vida, una representación digital de la realidad, una ontología de datos en lo que algunos han llamado datalogical turn. Así que el tamaño importa, ya que cambiando el volumen, la cantidad de datos manejados, ${ }^{2}$ se está cambiando en cierto modo la esencia de la realidad.

Este proceso de "datificación" de la realidad consiste en poner en un formato cuantificado y digital todo, para que pueda ser medido, registrado y analizado. Es decir, transformar todo en "información" (cuantificable). Es una antigua búsqueda de la Humanidad, pero, hoy en día, se desarrolla exponencialmente por medio de la digitalización y de los sistemas de TIC:

- Área espacial cuantificada (usada en forma de datos): geo-localización.

- Interacciones humanas (pensamientos, estados de ánimo, comportamiento), elementos intangibles de nuestra vida cotidiana: gráfico social (Facebook, Twitter, LinkedIn).

- Los actos más esenciales de la vida (sueño, actividad física, presión sanguínea, respiración...): monitorización, prendas de vestir, píldoras digitales, dispositivos de implante cerebral, relojes inteligentes, prótesis... (loB).

- Internet de las Cosas: "datificar" todo lo que nos rodea mediante la incrustación de chips, sensores y módulos de comunicación en los objetos cotidianos.

Todo este proceso resulta facilitado por los teléfonos inteligentes y la tecnología de computación barata. Tenemos las herramientas (estadísticas y algoritmos) y el equipo (procesadores digitales y almacenamiento) para manejar (y reutilizar) una enorme cantidad de datos.

Si pensamos en términos ontológicos, no son ya los átomos sino la información la base de todo lo que es. Un universo compuesto esencialmente de información (infosfera). Una nueva perspectiva de la realidad, del mundo, entendida como datos que pueden ser explorados y explotados. Se digitalizan todos los aspectos de nuestra vida y, no solo eso, se otorga un valor comercial a esa "datificación" de modo que nuestras actividades nos definen como un objeto mercantil ("somos el producto").

Por otro lado, la llamada ideología del 'dataísmo' es una nueva narrativa universal que regula nuestra vida y que viene legitimada por la autoridad de los algoritmos y de los datos masivos. El universo consiste en flujos de datos y el valor de cualquier fenómeno social o entidad está determinado por su contribución al procesamiento de datos. Y esto no es una teoría científicamente neutral porque pretende determinar lo que está bien y está mal con relación a un valor supremo, el "flujo de información": será bueno aquello que contribuya a difundir y profundizar el flujo de información en el universo y malo lo contrario. Un "dataísta", dice Harari, debe maximizar el flujo de datos conectándose cada vez a más medios y produciendo y consumiendo cada vez más información.

La digitalización es, por tanto, una actividad de tal trascendencia y capacidad transformadora que habrá que responder de ella. Ya hemos visto que la digitalización no solo transforma los objetos, sino también los hábitos, las costumbres o las relaciones, modificando los sistemas, ya sean sociales, económicos o naturales.

\footnotetext{
${ }^{2}$ La digitalización basada en IA y big data remite a tres elementos fundamentales: una enorme cantidad de datos, su reutilización y su manejo a través de nuevos medios (algoritmos) automáticos: Data Mining, Machine Learning (Deep Learning), Social Network Analysis, Predictive Analytics, Natural Language Processing and Visualization.
} 
Esta transformación se desarrolla a una gran velocidad e implica profundas modificaciones socioeconómicas y biofísicas en lo que se está llamando "la nueva era de los humanos" o Antropoceno. Este contexto se denomina "ciencia post-normal" (Funtowicz y Ravetz 2000) y se caracteriza por la incertidumbre sobre los hechos, los valores en disputa, los enormes desafíos (riesgos sistémicos como la actual pandemia o el cambio climático) y la necesidad de tomar medidas urgentes. Por ello, la digitalización requiere de reflexión ética.

\section{POR QUÉ ÉTICA}

Existe una cierta confusión y simplificación con relación a lo que significa hacer ética de la digitalización o de las tecnologías digitales. Muchas veces se formula como un conjunto de buenas intenciones con respecto al uso de las tecnologías, un recetario de prácticas o una trasposición de concepciones de la justicia al ámbito del desarrollo tecnocientífico. Pero la digitalización incorpora una moralidad, no es neutral valorativamente y por ello, como decíamos, conlleva la asunción de responsabilidades, a diferencia de otras acciones y actividades humanas que podemos considerar indiferentes y carentes de tal dimensión moral. Si, como decía Aranguren, la moral es nuestra segunda piel con la que "tocamos" a los demás, en el caso de las tecnologías vinculadas a la digitalización esto es más que evidente por su enorme impacto y capacidad transformadora. En consecuencia, habrá que "hacerse cargo" de ella, en afortunada expresión de Roberto R. Aramayo (1999).

Decimos que la digitalización tiene moralidad en la medida en que incorpora consideraciones sobre lo bueno y lo que es un deber. La responsabilidad consistiría en el deber de hacer la buena elección. 'Bien' y 'deber' son los dos términos morales fundamentales y el ser humano, en tanto que ser social, es necesariamente también un ser moral. Y la moral es un hecho social constatable por dos vías: 1. Un lenguaje específico: imperativos, expresiones normativas (deber, permiso, obligación, prohibición), expresiones valorativas (justo, recto, injusto, bien, mal...) relativas a aprobación o desaprobación. 2.- Su institucionalización parcial en el Derecho. (Sobre la relación compleja entre la moral y el derecho volveremos más adelante). Así, la moral es un hecho social (toda sociedad posee un código de normas) que es vivido colectiva e individualmente (dimensión social y personal de la moral).

Cuando justificamos racionalmente la moral, estamos haciendo ética. Por tanto, la ética es una reflexión acerca de la moral, acerca de los fundamentos de la propia conducta. Por ello, la ética (que es prescriptiva) tiene por objeto el establecimiento y justificación de criterios muy generales que pueden ser recomendados como preferibles y que permiten una fundamentación de las normas morales concretas ("algo es un deber") y, más en general, de los juicios morales ("algo es bueno"). ${ }^{3}$ También es así en lo que concierne a la actividad concreta de la digitalización a la que nos estamos refiriendo.

En este punto cabe plantear, siquiera brevemente, la cuestión del relativismo. ¿Es posible hablar de una 'moral universal'? ¿O tienen las normas morales solo valor relativo y cada pueblo e incluso cada individuo considera como deber y como bueno lo que le parece?

Este problema clásico, planteado ya en el siglo $\vee$ a.C. por los sofistas y en la llustración por el descubrimiento de la historicidad y de la dependencia social de los principios y reglas morales, se agudiza en nuestros días por el relativismo cultural planteado por la antropología: ni existen prácticas culturales universales ni se puede considerar que unas sean superiores a otras.

\footnotetext{
${ }^{3}$ Aranguren llama a la moral, "moral vivida" y a la ética "moral pensada". La metaética, por su parte, será la reflexión sobre las mismas nociones y conceptos de la ética y sus relaciones: bueno, deber, prohibición... (Aranguren,1994)
} 
Es un hecho incontrovertible que las normas morales varían de una sociedad a otra y a lo largo del tiempo y que, por ende, existen una enorme incertidumbre sobre los juicios morales. La pregunta crucial es si es posible que existan principios éticos universales. Sin embargo, el desacuerdo moral y la incertidumbre solo probarían la dificultad para encontrar respuestas definitivas sobre cuestiones morales, no que éstas no existan. Más aún, el pretendido desacuerdo puede estribar no en los principios morales básicos (por ejemplo, que no se debe dañar) sino en cuestiones de hecho o aplicación (sobre lo que daña o no, por ejemplo las emisiones de CO2) o en las diferencias de contexto y situaciones (no es lo mismo el valor de la salud para un diabético que para el que no lo es y, por tanto, existen conclusiones morales diferentes sobre el suministro de insulina, aunque el valor objetivo sea el mismo: la salud). Otra cosa es considerar ciertos valores y principios como absolutos, sin referencias contextuales (absolutismo moral). Sin embargo, puede haber bienes objetivos (salud, justicia...) que se concretan, modulan y varían de acuerdo a determinadas circunstancias. En última instancia, la cuestión es si es posible hacer mejores o peores elecciones morales de un modo justificado racionalmente (hacer ética). Al final, el relativismo moral, bajo la apariencia de tolerancia, esconde un posicionamiento "conservador" en favor del status quo o la moral dominante en una determinada sociedad.

Volviendo a lo que atañe a la reflexión ética, serán las diferentes teorías éticas las que establezcan criterios para justificar racionalmente normas y juicios morales. Estas teorías pueden ser de muy diversos tipos: materiales o formales, de principios o consecuencialistas, naturalistas o intuicionistas, perfeccionistas o de la virtud, axiológicas, del cuidado... (Singer 1991; Guisán 1995). - Para una breve historia de la ética puede consultarse Camps (2017).

\section{3. ÉTICA APLICADA A LA DIGITALIZACIÓN}

Se adopte uno u otro marco ético, o una combinación de varios, la reflexión ética sobre la digitalización constituye una ética aplicada en el sentido en que se pone el foco sobre una actividad concreta. Y este giro de la ética hacia la 'vida moral', hacia los casos y problemas morales sustantivos, no comporta un menoscabo de las tareas de análisis y de definición conceptuales sino que más bien las orienta y fructifica, rescatándolas de la 'torre de marfil' académica. Muchas de las teorías y muchos de los conceptos propios de la filosofía moral se están sometiendo al escrutinio implacable de su plasmación en la vida moral real y más en el ámbito de la digitalización: identidad, responsabilidad, justicia, discriminación, cuidado...

Las éticas aplicadas configuran una hermenéutica crítica de las actividades humanas y se caracterizan por dos notas características: la interdisciplinariedad y la participación pública. Decía Ferrater Mora que la ética sólo en manos de los filósofos no es muy buena idea -no es, como diría Aristóteles, cosa muy prudente (Ferrater y Cohn, 1994). La ética puede y debe estar también en manos de los biólogos, de los antropólogos, de los economistas, etc.; de hecho, puede y debe estar en manos de todos, porque todos tenemos intereses en ella. La ética aplicada exige adentrarse en cada uno de los ámbitos que tratamos y captar su propia lógica, como en este caso es la revolución digital. Por ello es preciso un trabajo interdisciplinar estrecho entre la filosofía, la ingeniería, la informática, el derecho...

En cuanto a la participación, ya hemos dicho que las cuestiones que abordan las éticas aplicadas producen importantes desacuerdos entre los expertos e implican la toma de decisiones, individuales y colectivas, y la asunción de riesgos en contextos de incertidumbre (la mencionada "ciencia post-normal"). Requieren, por tanto, deliberación pública y medidas políticas (control social). Por ello, las éticas aplicadas han de favorecer la participación social en el debate público, propiciando la información, la transparencia y la intervención de no expertos en la deliberación y toma de decisiones. 
En última instancia, la ética es un instrumento imprescindible para generar confianza en la revolución digital en la medida en que favorece la aceptación social y la apropiación por parte de la ciudadanía de dichas tecnologías. La ética, por tanto, promueve el empoderamiento tecnológico de la ciudadanía en términos de lo que podría denominarse "pacto tecno-social" (entre usuarios, empresas, estados) basado en principios éticos; esto es, un proceso de digitalización justo y socialmente responsable, alineado con los valores de una investigación e innovación responsables (RRI: responsible research and innovation) tal y como postula la Unión Europea. Esta estrategia incluye entre sus agendas la ética para fomentar la integridad científica, con el fin de prevenir y evitar prácticas de investigación inaceptables. La RRI es una retórica radical sobre la apertura y socialización de los procesos tecnocientíficos, en línea con la interdisciplinariedad y participación que caracterizan a las éticas aplicadas, y que se concreta en cuatro principios de gobernanza: anticipación, reflexividad, deliberación y responsabilidad.

Asimismo, la ética de la digitalización contribuirá a la definición de políticas públicas y a informar el derecho regulador necesario para abordar el proceso de transformación radical (disrupción) que suponen estas tecnologías.

Dicho esto, hay que añadir una salvedad. Existe un discurso casi ubicuo de la "ética para la digitalización" que, por ejemplo, no estaba en los orígenes de la IA y que se ha instalado con fuerza en este momento. Se trata de un discurso que muchas veces se alinea con los esfuerzos de las Big Tech por evitar restricciones legales a tecnologías controvertidas en una suerte de "lavado de cara" (whitewashing). Las grandes empresas de tecnología digital están utilizando la experiencia y la investigación en materia de ética para evitar las regulaciones gubernamentales (Ochigame 2019). Millones de dólares de Facebook, Amazon, Microsoft, Apple... van para centros e investigaciones en "digitalización ética", que se entiende como una práctica voluntaria frente a la regulación legal. La ética debería evitar ser utilizada como coartada.

\section{PRINCIPIOS}

El análisis ético ha dado lugar a un elenco de principios básicos que constituyen un punto de partida para el desarrollo e implementación de un diseño ético de las tecnologías vinculadas a la digitalización. Estos principios básicos nos ofrecerán un punto de partida para el análisis del caso moral concreto, para abordar los "riesgos éticos" que pueden entrañar los procesos de digitalización, centrando nuestra atención en las consideraciones básicas que habrá que tener en cuenta a la hora de formarse un juicio en tales situaciones.

Los principios pueden entenderse y justificarse de muy diverso modo: bien como generalizaciones prudenciales de la experiencia moral adquirida por los individuos y grupos a lo largo del tiempo (punto de vista empirista), bien como a prioris éticos universales y universalizables, bien como aspiraciones (telos) de buena vida, bien como virtudes o como deberes de cuidado - dependiendo del enfoque ético que hayamos adoptado como marco. ${ }^{4}$

\footnotetext{
4 John Stuart Mill los llamaba 'principia media' en su Lógica de las ciencias morales y Richard Hare, en El lenguaje de la moral, los definía como imperativos que prescriben determinados tipos de acciones en razón de determinadas características descriptivas que, siempre que se den cæteris paribus, obligan a actuar obedeciendo ese principio. Matizando esta definición, hay que decir que los principios, tal y como los contemplamos aquí, no prescriben actuaciones concretas de forma inmediata y directa, sino que más bien apuntan y orientan a la hora de actuar o formular normas concretas. Onora O'Neill (1989) entiende los principios como máximas mediante las cuales el agente organiza numerosas intenciones específicas, a modo de directrices para llevar una determinada actividad (en nuestro caso, las tecnologías digitales). Así, el contexto juega un papel importante ya que hace inteligible una acción en función de unas ciertas prácticas e instituciones.
} 
Sea como fuere, lo importante es que los principios no se aplican mecánicamente a las situaciones morales concretas, a modo de una aritmética. Los casos no se reducen a ser un mero ejemplo de lo que establecen los principios y la puesta en práctica de un principio nunca es la mera aplicación de un criterio general a un caso individual, de modo que se da una interacción entre los principios y las situaciones reales concretas, complejas y cambiantes. ${ }^{5}$

Además, un modelo de unos pocos principios genéricos para la ética de la revolución digital permite encuadrar en un marco más general, de forma comprehensiva, las buenas prácticas implicadas en el desarrollo de procesos de digitalización, así como informar al derecho y a las políticas públicas concretas.

Este conjunto de principios suele recogerse en documentos, declaraciones o códigos cuya pertinencia y efectividad (si no se quiere caer en una moralina inane o en la ética como mera cosmética) pueden analizarse en función de una serie de características y requisitos: participación, flexibilidad, adhesión, comunicación, monitorización, formación y difusión (Ausín 2018).

\section{DE LA ÉTICA AL DERECHO}

La revitalización del discurso ético en el contexto de la revolución digital ha tenido numerosos y diversos efectos y, entre estos, una reactivación de los paradigmas de comprensión de la función del derecho y de su relación con la ética. Como consecuencia de ello, se ha producido un doble fenómeno: por una parte, una abundancia, incluso saturación, de propuestas de principios éticos aplicados a la tecnología; y, por otra, una difuminación de los límites conceptuales y funcionales entre derecho y ética.

Estados, organizaciones internacionales, empresas, asociaciones, instituciones y organismos de distinta naturaleza han formulado una cantidad y variedad de decálogos de principios éticos prácticamente inabarcable hasta el punto de que parece estar configurándose en este ámbito una línea de investigación científica dedicada básicamente a sistematizar esas aportaciones. ${ }^{6}$ Quizá se está soslayando el hecho de que los principios son una consecuencia o resultado de la ética, como hemos señalado, y no la ética misma (Rességuier y Rodrigues, 2020: 3). Una saturación de principios éticos no necesariamente implica que se haya producido realmente un debate ético.

En cualquier caso, la atención dispensada al derecho ha sido apreciablemente menor. Entre los motivos explicativos de esa situación se aduce generalmente una resistencia, incluso, un rechazo natural a someterse a la rigidez de las normas jurídicas considerándolas un freno para el desarrollo tecnológico o la voluntad de desplazar el derecho mediante el establecimiento de principios éticos vocacionalmente universales.

El problema estriba en que no se puede sustituir el derecho mediante la ética porque no son estructuras cognitivas y funcionales permutables ni siquiera cuando, como ocurre con cierta frecuencia, muchos de sus principios y reglas son absolutamente iguales. La identidad en los contenidos materiales no implica, sin

\footnotetext{
5 "Los principios morales, cuando tienen pretensiones de aplicabilidad, tienen siempre un contenido que lleva la impronta de las situaciones para las que han sido invocados; los principios, para ser prácticos y tenidos en cuenta deben adaptarse a las situaciones; las situaciones y decisiones para ser entendidas y vividas en lo que está en juego en ellas desde el punto de vista moral, deben ser descritas y narradas en términos que las presentan en el horizonte teleológico al que apuntan los principios. Sólo desde la mediación permanente entre los principios que podemos invocar y las situaciones en las que tenemos que actuar se iluminan las decisiones concretas que podemos o debemos tomar." (Hortal 2002: 106).

${ }^{6}$ Una panorámica completa de las propuestas más relevantes puede consultarse en Fjeld et al., 2019 y en Zeng et al. 2019.
} 
embargo, identidad en los continentes - la ética y el derecho- , ni en las modalidades de aplicación, ni en las garantías que ofrecen cada uno de ellos, ni en las funciones, ni en los objetivos mismos que tienen asignados el derecho y la ética. Confundir ambos puede desencadenar dos efectos perversos: desvirtuar y anular la misión que tienen atribuido el uno o el otro. Si la ética se usa para desplazar al derecho, en una suerte de easy or soft solution o en un proceso ethics-washing to ethics-shopping (Wagner, 2018 y Yeung et al., 2019), como se ha comentado ya, se estará desvirtuando la función y el objetivo de la ética como reflexión crítica sobre el pensamiento y la realidad. Si el derecho es desplazado por la ética, se estará invalidando su función como instrumento preceptivo de ordenación de la vida en sociedad?.

La ética y el derecho pueden confundirse porque son modelos de pensamiento y de comportamiento y porque coinciden en algunos de sus valores, reglas y principios, pero no deben confundirse porque, incluso en esos casos, la calificación de cualquiera de ellos dentro de la ética o el derecho tiene consecuencias muy diferentes. La diferencia esencial radica en que la ética opera como un sistema autorreferencial que traduce valores, principios y reglas voluntarias. En cambio, el derecho es un sistema heterorreferencial que establece modelos de comportamiento obligatorios, sociales y generalmente colectivos. La inobservancia de un parámetro ético no genera sanciones, más allá de la reprobación o la vergüenza públicas, mientras que estas invariablemente se producen en caso de incumplimiento de un precepto jurídico. Los principios y reglas jurídicos no solo son obligatorios, sino que, además, su observancia está garantizada jurídica y judicialmente. No ocurre igual con los valores éticos (Rességuier y Rodrigues, 2020: 2).

Una norma jurídica puede ser universal si se adopta por el conjunto de los sujetos de la sociedad internacional que son los Estados. En cambio, una regla ética solo puede aspirar a ser universal porque no hay manera de imponer su respeto - ni fundamento, ni justificación para hacerlo - por tratarse, ontológicamente, de un valor de cumplimiento voluntario. No todas las personas, sociedades, culturas o civilizaciones comparten los mismos valores ni las jerarquías entre estos (pluralismo axiológico). Aunque algunos de ellos puedan ser generales o ampliamente compartidos, la diversidad ética como regla es, en sí misma, un valor que es necesario proteger incluso jurídicamente. En cualquier caso, tan importante es no confundir ética y derecho como reconocer y alimentar sus relaciones e interacciones.

\section{RELACIONES E INTERACCIONES ENTRE ÉTICA Y DERECHO}

Las relaciones entre la ética y el derecho superan el marco de análisis que ofrece la interdisciplinariedad como valiosísima regla de conocimiento científico. Si la necesidad de un conocimiento y una cooperación interdisciplinar es un principio extrapolable prácticamente a todas las esferas de acción humana y social, la ética y el derecho se sitúan en un estadio superior en términos conceptuales y funcionales tanto por las similitudes en sus contenidos, como por sus interacciones y aportaciones mutuas.

Materialmente, hay valores éticos, hay normas jurídicas y hay principios comunes éticos y jurídicos. Como ya se ha advertido, la ética y el derecho comparten contenidos materiales pero, al tratarse de sistemas - continentes - diferentes, su naturaleza, aplicación, consecuencias y efectividad son diferentes en cada caso. La dignidad es un valor común. No obstante, si se atenta contra ella, solo las normas y los procedimientos jurídicos pueden garantizar una reparación, además de la cesación de esa acción contraria

7 Un excelente análisis sobre las funciones y las relaciones entre ética y derecho puede verse en Rességuier y Rodrigues (2020). 
a derecho. A pesar de ello, puede ocurrir que esa sanción jurídica no sea suficiente para aliviar el daño producido sobre la conciencia de la dignidad como valor ético. Hay, asimismo, un proceso continuado de trasvase entre una y otro por sus mutuas y respectivas aportaciones.

La aportación del Derecho a la Ética es instrumental, funcional y material porque permite convertir en obligatorios valores que, por su naturaleza, originalmente en sede ética son voluntarios. Por su parte, la aportación que hace la Ética al Derecho puede definirse identificando sus tres funcionalidades principales:

1) Ética para el diseño normativo. El proceso de creación normativa se sustenta en una serie de principios $y$ valores, tanto jurídicos como éticos, al igual que los preceptos y normas resultantes del mismo responden a valores y principios de ambos tipos. El factor ético es parte integrante del debate jurídico legislativo y normativo porque en todo procedimiento de elaboración de normas, sea cual sea su contenido, hay un componente de reflexión crítica sobre la realidad y sobre las necesidades y valores de la sociedad. A ello se suma, en su condición de eje vertebrador del proceso, la propia idea de justicia como valor ético y aspiración jurídica. En el marco de la revolución digital, al tratar sobre la regulación, por ejemplo, de los vehículos autónomos se plantean tanto cuestiones técnicas como éticas y jurídicas. La norma resultante no puede obviar ninguno de esos elementos.

2) Ética para la reflexión normativa. Las normas, como la sociedad, tienen una naturaleza evolutiva, no son inmutables, ni permanentes en su mayoría porque, para cumplir sus objetivos, han de adaptarse a la evolución de la sociedad que están llamadas a regular y porque, para garantizar su funcionalidad, han de evaluarse de modo continuado en términos de eficacia. Tanto si hay cambios sociales como si hay evidencias de disfunciones, carencias o errores jurídicos, es preciso cuestionarse la validez o la efectividad misma de las normas. En el marco de ese proceso, es imprescindible la reflexión crítica que implica el debate ético. La protección de datos personales, que es un derecho vinculado al nacimiento de las TIC, por ejemplo, sigue siendo objeto de reflexión crítica porque las sucesivas innovaciones y desarrollos tecnológicos están cambiando recurrentemente los parámetros de ejercicio y de garantía de ese derecho.

3) Ética para la legitimación normativa. La autoridad de las normas y, también, su eficacia en términos absolutos dependen de su legitimidad tanto formal como material. La legitimidad formal deriva del propio sistema jurídico en la medida en que está garantizada cuando se respetan los procedimientos establecidos para la generación, aplicación y garantía del derecho. La legitimidad material, en cambio, traduce la conformidad y el consenso de los destinatarios de la norma sobre la necesidad y el contenido de la misma que se construye sobre la base de convicciones y valores mayoritariamente compartidos de naturaleza ética y moral. En el debate sobre la legalidad de las técnicas de reconocimiento biométrico, por ejemplo, no se puede soslayar el rechazo que genera mayoritariamente entre la población. Una norma que desconozca ese hecho está directamente abocada al fracaso.

\section{DERECHO APLICADO A LA DIGITALIZACIÓN}

La revolución digital no solo ha supuesto la generación de una dinámica constante de evolución y cambios exponenciales, sino que, además, ha tenido como efecto una normalización del cambio y de su velocidad. A pesar de que la idea de cambio traduce ontológicamente una ruptura de la normalidad, con la revolución digital, los cambios y la rapidez con que se producen son la verdadera normalidad. Los avances científicos y tecnológicos, incesantes y en progresión creciente en número y en entidad, se producen en márgenes temporales cada vez más reducidos de manera que la innovación continua constituye la normalidad en la era digital mientras que la ausencia de cambios resultaría ser la situación excepcional. 
La revolución tecnológica no se ha visto acompañada de una revolución jurídica, como tampoco de una revolución ética. Los valores éticos y los sistemas jurídicos no pueden -ni tampoco deben- evolucionar al mismo ritmo que la tecnología porque son constructos sociales, intersubjetivos y personales que responden a dinámicas de funcionamiento necesariamente distintas, más sosegadas y reflexivas. La explosión del debate ético en relación con las TIC no ha supuesto una revolución ética, esto es, una crisis, una alteración o una ruptura de la substancia y del entramado del discurso ético preexistente. Al contrario, se ha producido precisamente por la necesidad y la voluntad de aplicar ese substrato y aparato ético en el contexto de la revolución digital.

En el caso del Derecho, la situación es apreciablemente diferente por dos motivos: por una parte, porque no se ha producido un debate similar en alcance, amplitud y profundidad al que he tenido lugar en el ámbito ético; y, por otra parte, porque, también a diferencia de la ética, el discurso jurídico no puede limitarse a aplicar los principios y normas preexistentes en el contexto de la revolución digital. El derecho es un instrumento de ordenación de la vida en sociedad cuya efectividad para el cumplimiento de ese objetivo depende de su capacidad para adaptarse a los cambios y a las necesidades de la realidad que está llamado a regular.

La ética ha de marcar su impronta dentro de la revolución digital mientras que el derecho debe adaptarse a esta diferente realidad, pero no con la velocidad, ni necesariamente con el mismo alcance y la intensidad, de la revolución tecnológica. En cualquier caso, ni la revolución digital se ha producido o ha conducido a un vacío legal, ni el derecho puede soslayar la existencia y las consecuencias de la revolución digital. Ni la revolución digital puede prescindir o realizarse al margen del derecho, ni el derecho puede ignorar la revolución digital. La sociedad funciona mediante la tecnología y se organiza y regula a través del derecho.

Desde la perspectiva del Derecho internacional, que se ocupa del conjunto de las relaciones dentro de la sociedad internacional, la regulación de la revolución digital se está realizando sobre la base de reglas y técnicas jurídicas básicas. La primera es que existen principios y normas de naturaleza imperativa aplicables a cualquier ámbito de actividad que son igualmente aplicables en el contexto creado por la revolución digital, como ocurre, por ejemplo, con la obligación de respeto de los derechos y libertades básicas del ser humano. En segundo lugar, hay normas obligatorias asumidas por los Estados que puedan aplicarse, directamente o por analogía, en muchos de los ámbitos afectados por la revolución digital. Las normas sobre comercio electrónico o contratación online están diseñadas siguiendo los parámetros propios de las regulaciones de sus homólogas en el mundo físico. El derecho a la integridad mental, dentro de los llamados neuroderechos (Ausín y otros, 2020), estaría garantizado en la medida en que existe un derecho general de las personas a su integridad física y moral. En tercer lugar, hay normas que necesitan ser revisadas, pero no cuestionadas, cuando se trata de aplicarlas en el contexto de larevolución digital. La normativaen materia de responsabilidad civil sería un ejemplo a estos efectos. El derecho a la privacidad mental (Ausín y otros, 2020) requeriría una protección adicional a la que ofrece el concepto de privacidad tradicional y, en consecuencia, una adaptación normativa. En cuarto lugar, para terminar, habría que reformular o crear nuevas normas que respondan a materias o necesidades específicas diferentes o que no estaban previstas con anterioridad. Es el caso de la creación de un estatuto normativo para los artificios de inteligencia artificial, que puede ser o no dotarlos de personalidad jurídica. Sería el caso, también, de los derechos a la libertad cognitiva y a la continuidad psicológica que requerirían la formulación de normas para su reconocimiento y garantía.

La decisión sobre cualquiera de estas opciones cuando se trata de regular fenómenos novedosos, innovadores o disruptivos, está condicionada por distintos factores de índole política, económica, incluso cultural e ideológica, pero debe estar presidida por un principio motriz clave: la función del Derecho como instrumento de ordenación de la vida social frente a la realidad absoluta y radicalmente cambiante de la revolución digital. 


\section{DESAFÍOS JURÍDICOS EN LA REVOLUCIÓN DIGITAL}

Una mirada al Plan Estratégico de la ICANN 2012-2015 permite conocer algunos de los componentes del llamado Marco de Arquitectura de la Red 2030 que definen el paso de las siguientes etapas de la revolución digital. En primer lugar, el concepto de ManyNets supone que, en lugar de una red única, Internet será un mosaico de redes conectadas a través de pasarelas. Es un proceso que, además de su eventual justificación técnica, podría interpretarse como el resultado de una evolución en la que se ha pasado desde la idea original de un ciberespacio libre y abierto a la afirmación progresiva de la soberanía de los Estados sobre las infraestructuras, los recursos y los espacios cibernéticos. En segundo lugar, un nuevo modelo de IP está basado en la idea de una estrecha y sólida vinculación jurídica entre la dirección IP y el usuario que, si bien tendría utilidades potenciales, entre otros ámbitos, en la lucha contra las actividades cibernéticas maliciosas, posibilitaría también una vigilancia absoluta y generalizada de los usuarios por parte de cualquier sujeto, país, organización, institución, proveedor o intermediario. En tercer lugar, el desarrollo de nuevas tecnologías presagia un futuro próximo con avances constantes, incluso estructurales, como, entre otros, las comunicaciones de tipo holográfico, el Internet táctil para comunicaciones remotas gracias a la detección háptica, las redes de operaciones inteligentes o los gemelos digitales.

Estos cambios diseñan un futuro, entre utópico y distópico, en el que el derecho se enfrenta al reto de mantener su propia funcionalidad, defender su operatividad en términos de eficacia y conservar su razón de ser como instrumento de ordenación de la vida social articulado sobre la base de valores y principios creados y centrados en el ser humano. El derecho es un sistema antropocéntrico que reconoce y garantiza la función del ser humano como núcleo y eje vertebrador del conjunto de la sociedad y de la vida en su conjunto.

La revolución digital trae consigo tecnologías que asisten y ayudan a las personas y a la sociedad. Algunas de ellas pretenden emular, mejorar y perfeccionar al ser humano pero, más allá de esos loables propósitos, tienen el efecto perverso de situar a la persona dentro del entramado tecnológico como parte integrante del mismo o pueden acabar por convertirlo en una suerte de plataforma tecnológica. Sin negar los efectos benéficos de innovaciones como, por ejemplo, el "internet de los cuerpos" loB, hay que preguntarse por sus consecuencias éticas y jurídicas. Desde esta perspectiva se trata de un cambio de paradigma que afecta a la esencia misma del derecho por su naturaleza antropocéntrica. La igualdad podría o no seguir siendo un parámetro jurídico básico pero, en cualquier caso, habría de acomodarse a una realidad en la que la individualidad, como condición natural, y la perfectibilidad, como vocación superior del ser humano, pueden verse desplazadas por la eficacia y la perfección garantizada por la tecnología. Sin necesidad de entrar en una posible afectación de la dignidad, habría que preguntarse dónde estarían los límites de la mejora constante y la búsqueda de la eficacia y la perfección, como dinámicas intrinsecas propias de la tecnología, pero no necesaria ni principalmente de los seres humanos. La posibilidad de alcanzar la perfección a través de la tecnología podría desplazar o eliminar el derecho a ser imperfectos que es parte a su vez de la propia estructura, la naturaleza y la individualidad del ser humano. La máxima expresión de la imperfección humana es su propia finitud, que no solo es una categoría con una amplia significación desde diversas perspectivas (Hadjadj, 2012) sino, ante todo, un principio rector definitorio de la naturaleza y de existencia de los seres vivos y entre ellos, la especie humana.

\footnotetext{
${ }^{8}$ https://www.icann.org/es/system/files/files/strategic-plan-2021-2025-24jun19-es.pdf

${ }^{9}$ El debate sobre los límites de la mejora humana a través de la tecnología es un tópico central de la ética y la filosofía contemporáneas. Baste a modo de ejemplo las posiciones contrapuestas de Julian Savulescu (2012) y Michael Sandel (2007).
} 
Las tecnologías imperfectas carecen de sentido mientras que las perfectas exceden su sentido si la perfección y la eficacia se convierten en autoridades que desplazan los espacios deliberativos sobre los valores y los derechos donde se expresa el juicio humano. Como explica Habermas, la acción instrumental de las reglas técnicas "organiza medios que resultan adecuados o inadecuados según criterios de un control eficiente de la realidad". En cambio, "la acción estratégica solamente depende de la valoración correcta de las alternativas de comportamiento posible, que solo puede obtenerse por medio de una deducción hecha con el auxilio de valores y máximas" (Habermas, 1986). El solucionismo tecnológico no parece ser la mejor opción (Morozov, 2015), mientras que la tierra prometida de la singularidad (Kurzweil, 2012 y Winfield, 2019) no necesariamente ha de ser el paraíso o no ha de serlo para todos. La sacralización de la tecnología puede convertir en fines lo que no son sino medios $y$, sobre todo, puede revertir las prioridades y, entre ellas, la construcción histórica de un orden social basado en valores éticos y justos y en criterios de legitimidad democrática (Huws y Finnis, 2017). Tecnología, ética y derecho han de reacomodar sus funciones en el contexto de la sociedad digital. 


\section{REFERENCIAS BIBLIOGRÁFICAS}

- Aramayo, Roberto R. (1999). "Los confines éticos de la responsabilidad", en M. CRUZ Y R.R. ARAMAYO (coords.), El reparto de la acción. Ensayos en torno a la responsabilidad, Trotta, Madrid, 1999: 27-45.

- Aranguren, José Luis (1994). Obras Completas: Ética, vol. 2, Trotta, Madrid.

- Ausín, T. et alii (2020). Neuroderechos: Derechos humanos para las neurotecnologías. Diario La Ley, No 43, Sección Ciberderecho, 8 de Octubre de 2020, Wolters Kluwer.

- Ausín, T. (2018). “Códigos de buenas prácticas”, Eunomía. Revista en Cultura de la Legalidad 15: 239-248. DOI: https://doi.org/10.20318/eunomia.2018.4354

- Camps, V. (2017). Breve historia de la ética, RBA, Barcelona.

- Ferrater Mora, J y Cohn, Priscilla (1988). Ética aplicada, Alianza, Madrid.

- Fjeld, J. et al. 2019. Principled Artificial Intelligence. Mapping Consensus in Ethical and Rights-based Approaches to Principles for IA. Berkman Klein Center, Harvard University.

- Funtowicz, S.O. \& Ravetz, J.R. (2000). La ciencia posnormal: ciencia con la gente, Icaria, Barcelona.

- Guisán, E. (1995). Introducción a la ética, Cátedra, Madrid.

- Habermas, J. (1986). Ciencia y técnica como “ideología”. Tecnos, Barcelona.

- Hortal, A. (2002). Ética general de las profesiones, Desclée de Brouwer, Bilbao.

- Hadjadj, F. (2012). El paraíso en la puerta. Ensayo sobre una alegría que perturba. Ed. Nuevo inicio, Granada.

- Huws, C.F. y Finnis, J.C. (2017). "On computable number with an application to the AlanTuring problem", Artificial Intelligence Law, vol. 25, pp. 197-203.

- Kurzweil, R. (2012). La singularidad está cerca. Cuando los humanos trascendamos la biología, Lola Books, Berlín.

- Morozov. E. (2015). La locura del solucionismo tecnológico, Clave intelectual, Madrid.

- Ochigame, R. (2019), "The invention of 'Ethical Al'. How Big Tech Manipulates Academia to Avoid Regulation", The Intercept: https://theintercept.com/2019/12/20/mit-ethical-ai-artificial-intelligence/ [último acceso: 3 noviembre 2020].

- O'Neill, O. (1989). Constructions of Reason. Explorations on Kant's Practical Philosophy. Cambridge Univ. Press, 1989.

- Rességuier, A; Rodrigues, R. (2020). Al ethics should not remain toothless! A call to bring back the teeth of ethics. Big Data \& Society July-December 2020: 1-5. DOI: 10.1177/2053951720942541

- Sandel, M. (2007). Contra la perfección, Marbot, Barcelona.

- Savulescu, J. (2012) ¿Decisiones peligrosas? Una bioética desafiante, Tecnos, Madrid.

- Singer, P. (1991). A Companion to Ethics, Blackwell, Oxford.

- Wagner, B. (2018). "Ethics as an Escape from Regulation: From ethics-washing to ethics-shopping?", en HILDEBRANDT, M. (ed.). Being Profiling. Cogitas ergo sum, Amsterdam University Press. Ámsterdam, 2018.

- Winfield, A. (2019). "On the simulation (and energy costs) of human intelligence, the singularity and simulationism", en ADAMATZKY A. y KENDON V. (eds), From Astrophysics to Unconventional Computation. Emergence, Complexity and Computation, Springer, Cham. 
- Yeung, K. et al. (2019). "Al Governance by Human Rights-Centred Design, Deliberation and Oversight: And End to Ethics Washing" en DUBBER, M. y PASQUALE, F. (eds.), The Oxford Handbook of AI Ethics, Oxford University Press, Oxford.

- Zeng, Y. et al., (2019). Linking Artificial Intelligence Principles. Disponible en: https://arxiv.org/ abs/1812.04814. 